\title{
OS CONFLITOS TRABALHISTAS E A POSSIBILIDADE DA SUBMISSÃO À JUSTIÇA RESTAURATIVA
}

LABOR CONFLICTS AND THE POSSIBILITY OF
SUBMISSION TO RESTAURATIVE JUSTICE

\author{
Janete Rosa Martins ${ }^{1}$ \\ Nelci Lurdes Gayeski Meneguzzi² \\ Bianca Regina Caciamani ${ }^{3}$
}

\section{RESUMO}

A Justiça Restaurativa inserida nos modos não adversariais de solução de conflitos têm sido utilizada com sucesso em diversos segmentos sociais como em escolas, na resolução de conflitos familiares e comunitários, assim como em algumas situações que envolvem o Direito Penal. Diante disso, surge a problemática que envolve este breve estudo: será possível aplicar as técnicas da Justiça Restaurativa na resolução dos conflitos trabalhistas? A hipótese que se apresenta está voltada para a inviabilidade da aplicação da Justiça Restaurativa nos conflitos jurídico-trabalhistas, isto porque a relação existente entre empregado e empregador encontra-se em níveis hierárquicos diversos, justamente por isso tem-se a aplicação da principiologia do Direito do Trabalho,

\footnotetext{
${ }^{1}$ Doutora em Ciências Sociais pela UNISINOS - São Leopoldo/RS, Mestre em Direito pela UNISC - Santa Cruz do Sul/RS e Especialista em Direito Público e Bacharel em Direito pela UNIJUI - ljuí/RS, Professora da Pós-graduação Stricto Sensu em Direito - Mestrado e Doutorado e da Graduação em Direito, Editora da Revista Direito e Justiça: Reflexões Sociojurídicas, Pertencente ao Grupo de pesquisa Conflito, Cidadania e Direitos Humanos, vinculado a Linha de Pesquisa II - Políticas de Cidadania e Resolução de Conflitos, pesquisadora em Mediação URI - Universidade regional Integrada do Alto Uruguai e das Missões - campus de Santo Ângelo/RS/BRASIL: e-mail: janete@san.uri.br. Orcid: http://orcid.org/0000-0002-8014-8237. Endereço para contato - Rua Universidade das Missões, 464 - CEP: 98.802-470 Santo Ângelo-RS - Fone: 33137900

2 Doutoranda em Direito pela Universidade Regional do Noroeste do Estado do Rio Grande do Sul - UNIJUÍ. Mestra em Direito pela Universidade de Caxias do Sul - UCS. Especialista em Direito do Trabalho e Processo do Trabalho, pelo Complexo de Ensino Superior de Santa Catarina / CESUSC. Bacharela em Ciências Jurídicas e Sociais pela Universidade de Passo Fundo - UPF. Advogada. Docente de Ensino Superior com experiência na área de Direito: Direito do Trabalho, Processo do Trabalho e Direito Previdenciário. Atualmente é docente do Curso de Direito na Universidade Regional do Noroeste do Estado do Rio Grande do Sul - UNIJUÍ, nos campus de ljuí, Santa Rosa e Três Passos e na Universidade Regional Integrada do Alto Uruguai e das Missões - URI- Campus de Santo Ângelo, RS - Brasil. E-mail: nelcimeneguzzi@hotmail.com. Orcid: https://orcid.org/0000 - 0001 - 9770- 8395. Endereço para contato: Rua Universidade das Missões, 464 - CEP: 98.802-470 Santo Ângelo-RS - Fone :55 33137900

${ }^{3}$ Graduada em Direito pela Universidade Regional do Noroeste do Estado do Rio Grande do Sul - UNIJUí. E-mail: biancacaciamani@yahoo.com.br. Endereço para contato: Rua do Comércio 3000 - campus Universitário ljui/RS - $98700-000$
} 
especialmente o princípio da proteção que faz com que as partes da relação de emprego cheguem ao mesmo patamar. No entanto, entende-se possível a aplicação da Justiça Restaurativa nos conflitos decorrentes da gestão das atividades econômicas exploradas pelo empregador, como meio de resolver eventuais conflitos dessa ordem. Metodologicamente, o estudo tem caráter exploratório, pois enfatiza as causas e consequências relacionadas à problemática por intermédio da coleta de dados. Para tanto, utiliza o método de abordagem hipotético-dedutivo, sendo observados a essência do objeto de estudo, os procedimentos de seleção bibliográfica e a leitura do material selecionado, que permitiram uma reflexão crítica acerca do tema pesquisado e, por fim, a exposição dos resultados obtidos.

Palavras-chave: Justiça Restaurativa. Justiça Restaurativa Trabalhista. Resolução de Conflitos.

\section{ABSTRACT}

Restorative justice inserted in non-adversarial ways of conflict resolution has been used successfully in several social segments, such as schools, in the resolution of family and community conflicts, as well as in some situations involving Criminal Law. In view of this, the problem that surrounds this brief study arises: is it possible to apply the techniques of Restorative Justice in the resolution of labor conflicts? The hypothesis that is presented is aimed at the infeasibility of the application of Restorative Justice in legallabor conflicts, this is because the existing relationship between employee and employer is at different hierarchical levels, precisely for this reason the application of the principle of Law Labor, especially the principle of protection that makes the parts of the employment relationship reach the same level. However, it is considered possible to apply Restorative Justice in conflicts arising from the management of economic activities explored by the employer, as a means of resolving eventual conflicts of that order. Methodologically, the study has an exploratory character, as it emphasizes the causes and consequences related to the problem through data collection. For that, it uses the hypothetical-deductive approach method, observing the essence of the object of study, the bibliographic selection procedures and the reading of the selected material, which allowed a critical reflection on the researched theme and, finally, the exposition of results obtained.

Keywords: Restorative Justice. Conflict resolution; Restorative. Labor Justice.

\section{CONSIDERAÇÕES INICIAIS}

O presente artigo tem como finalidade a aplicação da justiça restaurativa nos conflitos trabalhistas. O problema levantado volta-se para a análise do sistema de 
justiça em vigor, preponderantemente focado na sanção que será imposta a quem desrespeita determinada norma trabalhista, sob um viés eminentemente econômico e que nem sempre atende plenamente aos anseios de quem sentiu na pele essa transgressão, pode ser complementado pelo sistema restaurativo.

Denota-se que até o presente momento as experiências de aplicação da justiça restaurativa no Brasil têm ocorrido basicamente em conflitos que envolvem crianças e adolescentes, questões familiares, de violência doméstica e crimes de menor potencial lesivo.

A aplicação de tais meios no país ainda é, de uma forma geral, recente, mas já se pode observar uma crescente utilização da conciliação para as causas consumeristas e a mediação para conflitos familiares, por exemplo, de forma que este modelo restaurativo, focado não apenas na reparação material do dano, mas na reparação dos laços emocionais e sociais rompidos, poderia também ser devidamente adaptado à realidade trabalhista brasileira.

Cientes da profundidade desses questionamentos e da gama de direitos envolvidos no debate, não se tem a pretensão de trazer respostas definitivas para 0 objeto do presente estudo, mas sim tecer algumas considerações a fim de melhor esclarecer os temas que giram em seu entorno. Com o objetivo de fomentar o debate que se afigura não apenas oportuno, mas necessário, uma vez que tal meio alternativo de solução de conflito é um instrumento de enorme importância para o fortalecimento e a melhoria da distribuição da justiça, que complementa e auxilia o papel das instituições judiciárias, a fim de proporcionar uma melhoria na solução e na administração dos mais diversos conflitos trabalhistas.

\section{OS CONFLITOS DECORRENTES DAS RELAÇÕES INDIVIDUAIS DE LABOR}

Na seara trabalhista, é notório que atualmente os conflitos de interesses são predominantemente resolvidos por meio das reclamações trabalhistas, das quais, segundo Souza Lara $(2013$, p.121) aproximadamente metade terminam em conciliação 
judicial na primeira audiência, enquanto que para a outra metade, a solução normalmente é dada por sentença, ato pelo qual o juiz decide a lide, em nome do Estado, entre as partes litigantes no processo.

Nos conflitos decorrentes das relações individuais de trabalho discute-se a possibilidade de utilizar pelos menos três métodos indicados pela doutrina para solucioná-los: a autodefesa, a autocomposição e a heterocomposição.

A autodefesa, segundo Jorge Neto e Cavalcante (2019, p. 98) "compreende o ato pelo qual alguém defende seus direitos e interesses pelas suas próprias forças". Este método não tem sido reconhecido para a solução de conflitos individuais decorrentes das relações de trabalho tendo em vista as cominações legais inscritas no Código Penal Brasileiro (art. 345, C.P.), no sentido de não ser possível que o empregado faça justiça pelas próprias mãos porque caracterizará, salvo em situações de legítima defesa, ilícito penal.

No entanto, nas relações coletivas de trabalho a autodefesa se apresenta como possível quando determinada categoria profissional opta pelo exercício do direito de greve (Lei n. 7.783/89), sendo este um meio de autotutela à disposição dos operários para suprir a lacuna de proteção legal ou proteção social. Enfatizando-se que a greve é um direito social fundamental (art. 9 da Constituição Federal do Brasil) que pode ser exercido coletivamente pelos empregados contra a categoria patronal. Ressalta-se que a greve por si só não resolve o conflito, mas é uma importante ferramenta que pode fazer chegar a heterocomposição ou autocomposição.

A autodefesa nos parece o meio mais primitivo de solução de conflitos. É, portanto, segundo Bezerra Leite (2019,cp.151) "um método de solução direta, mediante imposição do interesse do mais forte sobre o mais fraco".

Outro método de resolução de conflitos trabalhistas indicado é a autocomposição tratando-se de uma negociação direta entre as partes, observados os direitos já adquiridos e as hipóteses de nulidades trabalhistas (art. 9 e 468 da CLT).

Nas palavras de Bezerra Leite (2019, p.151) a autocomposição "consiste em uma técnica em que os litigantes, de comum acordo e sem emprego da força, fazem 
concessões recíprocas mediante ajuste de vontades". Este método de autocomposição extraprocessual trabalhista é utilizado de forma mais intensa nas negociações coletivas, ou seja, nas convenções e acordos coletivos de trabalho.

Nas relações individuais é possível verificar aplicação da autocomposição entre as partes quando existir a renúncia, a aceitação ou a transação. Entretanto Delgado (2019) ocorre a renúncia quando o titular de um direito por ato unilateral abre mão em favor de alguém. Já a aceitação se verifica quando uma das partes reconhece o direito de outra e sua conduta se dá nesse sentido e a transação ocorre quando as partes fazem concessões recíprocas para solucionar os conflitos.

A legislação consolidada também prevê a Comissão de Conciliação Prévia (CCP) como sendo um método autocompositivo extraprocessual inserto nos artigos 625-A a $625-\mathrm{H}$ que objetiva tentar conciliar os conflitos individuais de trabalho entre empregadores e empregados, na busca da solução extrajudicial dos conflitos individuais de trabalho, atuando ao lado da função jurisdicional do Estado, mas não como substitutivo desta. As CCPs servem para promover o diálogo direito entre empregado e patrão naquilo que se referir aos conflitos individuais, e também em âmbito coletivo a exemplo do que ocorre nos Núcleos Intersindicais de Conciliação Trabalhista.

Além disso, tem-se a heterocomposição como possibilidade de resolução dos conflitos trabalhistas e esta ocorre quando um terceiro decide em nome das partes obrigando-as à decisão. Trata-se de uma solução direta do conflito e as principais formas de heterocomposição são a arbitragem, a jurisdição e a conciliação.

Cassar (2015, p.143) deixa claro que a forma de solução dos conflitos laborais "caracteriza-se pela intervenção de um terceiro na disputa entre dois ou mais sujeitos, podendo decidir a questão ou aconselhar as partes para que cheguem a uma solução". A forma de heterocomposição denominada de arbitragem somente pode ser aplicada, no Brasil, para as situações que envolvam direitos patrimoniais disponíveis conforme disposto na Lei n. 9.307/96 em seu artigo 1ํe ocorrerá quando as partes elegem para a 
resolução de seu conflito um terceiro, denominado árbitro que elaborará o laudo arbitral decidindo o conflito.

A jurisdição é o modo heterocompositivo mais utilizado para solucionar os conflitos trabalhistas sendo exercido conforme Delgado (2019, p. 1735) por um "segmento específico do poder institucionalizado do Estado, que é o Judiciário. Os juízes e tribunais são os agentes especializados para o exercício da jurisdição, que se faz em um estuário formal próprio, o processo judicial". A resolução do conflito submetido a apreciação da via jurisdicional se consuma com a sentença.

Por outro lado, na Justiça do Trabalho há fortemente a aplicação da conciliação tanto de forma judicial como extrajudicialmente. A conciliação pode ser compreendida como uma forma de solução de conflitos heterocompositiva em que as partes em conflito dirigidas por um terceiro com o objetivo de implementar um resultado diferente daquele primitivamente objetivado pelas partes, normalmente há mútuas concessões para que a conciliação possa se estabelecer.

As conciliações extrajudiciais podem ocorrer, de comum acordo pelas partes, extrajudicialmente, e posteriormente ser submetido à Justiça do Trabalho para que seja homologado, observadas as peculiaridades do artigo 855-B introduzido na legislação consolidada pela Lei 13.467/2017.

Já as conciliações judiciais decorrem de atos praticados perante a Justiça do Trabalho, sendo assim um "ato judicial, mediante o qual as partes litigantes, sob interveniência do juiz, ajustam solução transacionada sobre matéria objeto de processo judicial"(DELGADO, 2019, p.1737). Assim, os conflitos submetidos ao judiciário trabalhista sempre serão sujeitos à conciliação (art. 764 da CLT) podendo ocorrer em qualquer fase da audiência (852-E da CLT).

A Justiça do Trabalho é o ramo do judiciário que mais concilia. De acordo com o Conselho Nacional de Justiça (CNJ) $24 \%$ dos casos solucionados por meio de acordo e seu Relatório Justiça em Números 2019. A conciliação é política adotada pelo CNJ desde 2006 e integra a Justiça do Trabalho e faz parte do processo trabalhista desde a criação. 
Em 2010 a Resolução CNJ 125/2010, criou os Centros Judiciários de Solução de Conflitos e Cidadania (CEJUSCS) e os Núcleos Permanentes de Métodos Consensuais de Solução de Conflitos (NUPEMEC) com o objetivo de fortalecer e estruturar unidades destinadas ao atendimento dos casos de conciliação, assim como o Conselho Superior da Justiça do Trabalho (CSJT) promove anualmente a Semana Nacional de Conciliação Trabalhista.

Ocorre que, em decorrência da complexidade do ser humano e seus conflitos, a legislação trabalhista não consegue prever todas as formas de disputas e nem mesmo seus modos de superação. Logo, mesmo que as partes cheguem diante do Poder Judiciário narrando certa questão que lhes aflige buscando uma resposta para tal situação, na justiça atual, o verdadeiro conflito parece não vir à tona ou quase ser abafado na discussão, que geralmente acaba sendo travada apenas entre os profissionais do Direito e não efetivamente entre os interessados(Milhem, 2016, p.150).

A Constituição Federal de 1988 (CF) consagra em seu bojo o acesso a justiça, nesse mesmo sentido estão os Tratados Internacionais de Direitos Humanos garantindo a possibilidade de que indivíduos possam recorrer à justiça para a proteção de seus direitos, isso significa necessariamente que a judicialização seja sempre a ferramenta para a solução do conflito ou o modo mais adequado de aliviar o sofrimento das vítimas, uma vez que, em algumas situações esse processo possa ser doloroso e inclusive exacerbar o conflito ao invés de contribuir para a paz social.

Além do mais, apesar de as partes serem atendidas pelo Poder Judiciário, obtendo algum tipo de resposta a suas demandas, é possível que muitas vezes saiam da presença do magistrado com a sensação de que a justiça não tenha sido efetivamente feita (Milhem, 2016, p.150-166). Isso porque o próprio empregado que recebe uma indenização, ou o empregador a quem é reconhecido que cumpriu com todos os seus encargos, podem permanecer frustrados após o julgamento de uma ação trabalhista, principalmente nos casos em que havia alguma relação de confiança e quase familiaridade entre reclamante e reclamado, que muitas vezes ocorre em empresas de menor porte e com número reduzido de funcionários 
Não são em todas as situações que tais lacunas são supridas pelas decisões judiciais tradicionais, pois nem sempre o interesse monetário é o mais importante aos litigantes, eis que muitas vezes o reclamante apenas quer reconhecimento ou mesmo quer ser ouvido e sair do Poder Judiciário com a sensação de que efetivamente fora atendido, teve suas necessidades supridas e foi ouvido.

Ao nosso sentir, é justamente neste contexto que se insere a justiça restaurativa, que permite compreender que no processo de justiça, a busca pela verdade e a compensação pelos danos sofridos não estão limitados apenas a punir uma das partes ao mesmo tempo em que a outra parte será atribuído o ganho da causa. Trata-se de compreender que a justiça pode ser feita proporcionando aos envolvidos um exercício mais participativo, com vistas a restaurar ou transformar os laços sociais afetados pelo conflito.

Segundo o que escreve Nogueira(2018,s.p) é possível notar que, em que pese tenham sido tomadas algumas medidas, como a criação dos Juizados Especiais e também o aumento de varas e magistrados, tais providências não foram a solução para todas as questões existentes, pois apesar de serem mais céleres e garantirem o acesso à justiça, não resolveram alguns dos problemas judiciários, visto que nem sempre a solução esperada pelas partes litigantes é uma sentença (que muitas vezes não é capaz de suprir os interesses das partes e pode gerar ainda mais conflitos que posteriormente poderão ser objeto de nova demanda judicial).

Diante da imensa judicialização de ações capazes de abarrotar o sistema jurídico e também da notória ineficiência do Poder Judiciário como instrumento capaz de solucionar toda e qualquer espécie de litígio, é que o Poder Judiciário brasileiro sentiu a necessidade de adotar medidas alternativas para a resolução de conflitos tanto judiciais como extrajudiciais, como por exemplo a mediação e a conciliação, que têm conquistado cada vez mais espaço em razão da eficácia obtida na resolução de conflitos existentes nas mais diversas áreas do direito.

Visualizou-se, assim, os métodos consensuais de resolução de conflitos como uma boa alternativa às demandas judiciais, eis que desafogariam o assoberbado Poder 
Judiciário e estimulariam o diálogo como meio para a composição efetiva do conflito, tanto é que o Código de Processo Civil é expresso ao determinar que o Estado deve promover, sempre que possível, a solução consensual dos conflitos (art. $3^{\circ}, \S^{\circ} 2^{\circ}$ ).

$\mathrm{E}$ ao elencar meios alternativos de resolução de conflitos, não há como não mencionar a Justiça Restaurativa, que se trata de um método eficaz de acesso à justiça, efetivada pelas próprias partes, que são as verdadeiras protagonistas da solução a ser aplicada e que permite o reconhecimento e o restabelecimento de eventuais relações rompidas após a ocorrência de um conflito, com o alcance da justiça de cada um dos envolvidos.

As exigências da nossa sociedade atual fazem com que o nível de estresse das pessoas aumente, eis que no dia a dia de cada um surgem cobranças das mais variadas fontes, seja pela falta de tempo, seja uma dificuldade financeira, uma meta no trabalho ou até mesmo um desafio pessoal, o que muitas vezes acaba tornando os seres humanos mais intolerantes e impacientes, mudando seu comportamento e muitas vezes até acarretando o surgimento de diversos conflitos.

Em razão dessas situações acima mencionadas, as relações entre os indivíduos têm se apresentado cada vez mais complicadas, sejam elas no círculo familiar, na sociedade ou até mesmo no trabalho, o que leva ao surgimento de vários conflitos e também o aumento do ajuizamento de ações para solução de tais impasses. Ocorre que a sociedade, por muito tempo, restou carente de um método capaz de voltar a fazer uso do entendimento através da palavra, a fim de apaziguar as relações, expor os fatos e compreender a situação alheia no objetivo de se chegar a um "denominador comum", eis que a justiça comum muitas vezes apenas decidia qual a melhor solução para o caso e aplicava uma sentença que nem sempre oferecia as respostas esperadas pelas partes.

E é nesse contexto que surgiram os meios alternativos de resolução de conflitos, como a conciliação e mediação, como exemplo, bem como a Justiça Restaurativa, a qual possui o objetivo de aperfeiçoar a técnica de solução dos litígios ao utilizar a 
DOI 10.20873/uft.2359-0106.2021.v8n2.p269-292

prática de círculos restaurativos e a comunicação não violenta (CNV), dentre outros métodos que visam a manutenção da paz em todas as situações conflituosas.

\section{A JUSTIÇA RESTAURATIVA E SUA ESPECIFICIDADES: CONTORNOS CONCEITUAIS}

Para compreender a justiça restaurativa e suas especificidades necessário, trazer a luz o conceito adotado por Howard Zehr (2008, p. 257) que entende que a "justiça restaurativa é um encontro entre as pessoas diretamente envolvidas numa situação de violência ou conflito, seus familiares, amigos e comunidades."

Nesse encontro, segundo Zehr (2008) há a previsão de um roteiro elaborado previamente por aquele que irá coordenar o encontro como forma de proporcionar um espaço seguro e protegido, onde as pessoas possam abordar o problema que as cerca e construírem possíveis soluções para este, enfocando as necessidades a abordagem tem foco nas necessidades emergentes do conflito como modo de aproximar e corresponsabilizar os participantes por meio de um plano de ações que objetiva restaurar laços sociais e compensar danos, gerando compromissos de comportamentos futuros mais harmônicos. Relevante destacar que a Justiça Restaurativa está enfocada nos danos e nas necessidades que deste decorrem tanto da vítima omo do ofensor e da comunidade, abordando-os com base na aplicação de princípios cooperativos.

A Justiça Restaurativa transcende a busca por culpados e vingança e supera a visão dos participantes como vítima, ofensor e testemunhas, pois vê ali pessoas. Ela incentiva a comunicação, oportunizando que as pessoas envolvidas participem do diálogo expondo suas necessidades, no intuito de retomar a harmonia e o equilíbrio entre todos, visando, também, desenvolver ações construtivas para restaurar laços sociais, compensar danos e criar compromissos mais harmônicos (2019, s.p).

O primeiro passo na justiça restaurativa é atender às necessidades imediatas, especialmente as da vítima. Depois disso a justiça restaurativa deveria buscar identificar necessidades e obrigações mais amplas. Para tanto o processo deverá, na medida do possível, colocar o poder e a responsabilidade nas mãos dos diretamente envolvidos: a vítima e o ofensor. Deve haver espaço também para o envolvimento da 
DOI 10.20873/uft.2359-0106.2021.v8n2.p269-292

comunidade. Em segundo lugar, ela deve tratar do relacionamento vítima-ofensor facilitando sua interação e a troca de informações sobre o acontecido, sobre cada um dos envolvidos e sobre suas necessidades. Em terceiro lugar, ela deve se concentrar na resolução dos problemas, tratando não apenas das necessidades presentes, mas das intenções futuras (ZEHR, 2008, p. 192).

$\mathrm{Na}$ Justiça Restaurativa as partes são os verdadeiros protagonistas da melhor solução a ser encontrada para o litígio. Logo, enquanto o foco da justiça retributiva é o passado, com atribuição de culpa a alguma das partes e ignorando-se a figura do ofendido, no contexto da restauração o foco é o futuro, pois busca-se a construção de uma solução para o problema, atribuindo-se à vítima um papel ativo, com ênfase nas suas reais necessidades. Segundo Pedro Scuro Neto (2000, s.p):

[...] "fazer justiça" do ponto de vista restaurativo significa dar resposta sistemática às infrações e a suas consequências, enfatizando a cura das feridas sofridas pela sensibilidade, pela dignidade ou reputação, destacando a dor, a mágoa, o dano, a ofensa, o agravo, causados pelo malfeito, contando para isso com a participação de todos os envolvidos (vítima, infrator, comunidade) na resolução dos problemas (conflitos) criados por determinados incidentes. Práticas de justiça com objetivos restaurativos identificam os males infligidos e influem na sua reparação, envolvendo as pessoas e transformando suas atitudes e perspectivas em relação convencional com sistema de Justiça, significando, assim, trabalhar para restaurar, reconstituir, reconstruir; de sorte que todos os envolvidos e afetados por um crime ou infração devem ter, se quiserem, a oportunidade de participar do processo restaurativo.

No sistema atual, a simples condenação (que no caso da justiça trabalhista muitas vezes consiste em uma condenação monetária), geralmente não considera os fatores emocionais e sociais envolvidos no litígio (fundamentais para que as pessoas afetadas pela transgressão da norma restaurem os sentimentos e relacionamentos positivos). A Justiça Restaurativa, por sua vez, seria capaz de preencher as necessidades emocionais daquelas pessoas envolvidas no conflito, além de funcionar como um elemento eficaz para o desenvolvimento de uma cultura voltada à paz social.

Afirma-se, assim, que a Justiça Restaurativa não se concentra no passado e na culpa, mas trabalha exatamente com a ideia de se voltar para o futuro e para 
restauração dos relacionamentos, pois enquanto a justiça convencional diz: "você fez isso e tem que ser castigado!", voltada à incumbência do empregador de arcar com os danos sofridos pelo empregado, a justiça restaurativa pergunta: "o que você pode fazer agora para restaurar isso?", tratando o ambiente de conflito em sua forma mais ampla e humana, Gomes Pinto(2005, p. 24).

É nesse sentido que surge a reflexão acerca da possibilidade de aplicação dos princípios e procedimentos da Justiça Restaurativa - que foi idealizada inicialmente para o desenvolvimento da cultura da paz na esfera criminal para a construção de novos mecanismos de resolução de conflitos na seara trabalhista brasileira, pois o sistema de justiça em vigor, preponderantemente focado na sanção que será imposta aquele que descumprir a norma trabalhista sob um viés eminentemente econômico, nem sempre atende plenamente aos anseios de quem sentiu na pele essa transgressão, Lara (2006, p.26).

Para que o propósito da Justiça Restaurativa encontre um solo fértil para se desenvolver e ser aplicada será necessária uma metodologia que proporcione a transformação nas pessoas de modo a que no futuro estas queiram utilizá-la, assim Marshall Rosenberg(2006, p. 21-222) propõe a utilização da Comunicação Não Violenta (CNV) e se baseia,

em habilidades de linguagem e comunicação que fortalecem a capacidade de continuarmos humanos, mesmo em condições adversas. Ela não tem nada de novo: tudo que foi integrado à CNV já era conhecido a séculos. O objetivo é nos lembrar do que já sabemos - de como nós, humanos, deveríamos nos relacionar uns com os outros - e nos ajudar a viver de modo que se manifeste concretamente esse conhecimento. A CNV nos ajuda a reformular a maneira pela qual nos expressamos e ouvimos os outros Rosenberg (2006, p.22).

Este método tende a proporcionar momentos reflexivos que auxiliam na forma como se deseja conduzir a resolução do conflito incluindo nesse processo a capacidade de se estabelecer um olhar mais tolerante e humano frente ao oponente proporcionando segundo Rosenberg (2006, p. 22) umas "respostas conscientes, 
DOI 10.20873/uft.2359-0106.2021.v8n2.p269-292

firmemente baseadas na consciência do que estamos percebendo, sentindo e desejando. Somos levados a nos expressar com honestidade e clareza, ao mesmo tempo que damos aos outros uma atenção respeitosa e empática.

Para Lara (20013), em que pese a Justiça do Trabalho ser o ramo do Judiciário brasileiro que esteja em melhor situação e ser conhecida pelo uso efetivo da conciliação nas audiências de sua competência, ela ainda não se utiliza da Justiça

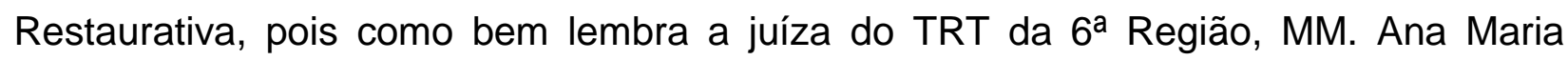
Soares R. de Barros (2006, p.1), "todos os projetos pilotos estão na Justiça Comum".

A Justiça Restaurativa passou a integrar o ordenamento jurídico brasileiro com a Resolução 225/2016 do Conselho Nacional de Justiça, que a define "como um conjunto ordenado e sistêmico de princípios, métodos, técnicas e atividades próprias que visa a conscientização sobre os fatores relacionais, institucionais e sociais motivadores de conflitos e violência, e por meio do qual os conflitos que geram dano, concreto ou abstrato, são solucionados de modo estruturado". Definição a partir da qual já acontecem práticas de Justiça Restaurativa em várias áreas do País e inclusive por diversas metodologias.

Ocorre que, apesar de toda sua importância, a implantação do método restaurativo de resolução de conflitos muitas vezes ainda se restringe à área cível e criminal, não sendo encontrado nas Varas do Trabalho, onde sua introdução facilitaria e muito a resolução dos dissídios trabalhistas. No Direito do Trabalho tem-se apenas as Comissões de Conciliações Prévias e os Acordos Coletivos de Trabalho ou Convenções Coletivas de Trabalho para tentar resolver os conflitos sem a necessidade de todo um processo judicial, métodos esses que também são passíveis de vício.

A implementação da justiça restaurativa na seara trabalhista é, portanto, uma medida a ser pensada, pois em muitos dos casos levados à Justiça do Trabalho, as práticas restaurativas poderiam trazer excelentes resultados, contribuindo para a plenitude da aplicação dos princípios que regem tal área do Direito. Além do mais, se tais práticas restaurativas já estão sendo utilizadas em diversos conflitos considerados mais graves em nossa sociedade e ordenamento jurídico, como aqueles que têm 
consequências criminais, por exemplo, não existem motivos para que não possam ser aplicadas também aos conflitos trabalhistas.

Na obra "Trocando as lentes" Zehr (2008, p. 48), um dos textos base da Justiça Restaurativa, analisa as relações de poder existentes dentro de qualquer conflito e reflete que geralmente o conflito é causado justamente por um desequilíbrio de poder, que no caso trabalhista podemos mencionar aquele decorrente de um desentendimento ocorrido entre o empregador e empregado, de modo que a utilização do diálogo em um círculo restaurativo poderia causar nos envolvidos uma nova a promissora relação de igualdade, de empoderamento e também responsabilidade, vindo a solucionar os desentendimentos existentes de uma maneira muito mais humana e eficaz.

Entretanto, em que pese a brilhante ideia de aplicação da justiça restaurativa à seara trabalhista, Lara (2013), cumpre mencionar que, nem todo conflito trabalhista poderia ser submetido à Justiça Restaurativa, eis que nas situações em que o conflito for exclusivamente pautado no fator econômico (como o pagamento de horas extras ou verbas indenizatórias, por exemplo), não há efetivamente o que restaurar.

Além do mais, também não se aplicaria a Justiça Restaurativa àquelas situações em que as partes se recusarem a se submeter aos círculos, uma vez que no processo restaurativo a consensualidade é um dos elementos essenciais, de modo que o procedimento somente ocorrerá se os envolvidos no conflito concordarem com a realização de tal prática, o que reforça ainda mais o aspecto complementar da Justiça Restaurativa, que não visa superar os sistemas de justiça em vigor, mas tão somente oferecer uma nova abordagem para determinados tipos de conflitos. Tanto é que caso o processo restaurativo não culminar em um acordo de vontade entre os envolvidos, ainda que de forma parcial, o processo seguiria o seu rito original.

Sendo assim, é certo que o âmbito de aplicação das práticas restaurativas na seara trabalhista seria restrito. Porém, não se pode duvidar da potencialidade transformadora da Justiça Restaurativa, que se baseia em uma metodologia totalmente diferenciada, que privilegia o diálogo e o entendimento das partes, indo de encontro à 
metodologia retributiva que atualmente é predominante nos espaços oficiais de resolução de conflito.

Nos círculos restaurativos, Lara, (2013) é oferecido aos envolvidos um ambiente de conversa mais informal, que é assistido por profissionais qualificados e com formação diversificada (como especialistas do ramo da psicologia e do serviço social, por exemplo), pois neste espaço não é apenas a lide jurídica que é importante, mas também as questões emocionais e sociais, que muitas vezes acabam ficando à margem do processo de resolução de conflitos e por meio deste método podem ser discutidas de forma que seja dado ao conflito a solução mais abrangente possível.

A Justiça do Trabalho, não obstante talvez seja o ramo do Judiciário brasileiro que esteja em melhor situação a ser conhecida pelo uso efetivo da conciliação nas audiências de sua alçada, ainda não atentou para o potencial pacificador da Justiça Restaurativa e que, se bem desenvolvida a hipótese, pode, muito bem, ser excelente ferramenta de construção de uma forma adequada de tratamento dos conflitos trabalhistas.

Isso porque os métodos restaurativos iriam garantir que os conflitos trabalhistas fossem resolvidos de modo justo para o trabalhador, e que sua dignidade fosse preservada ou restabelecia através do acesso à Justiça de forma plena, eis que ao trazer o conflito para a análise mais aprofundada e tentar compreendê-lo desde sua causa para então buscar uma solução do conflito, transformando-o em algo positivo para as partes a fim de restabelecerem os vínculos trabalhistas e tentarem se compreender novamente, o método restaurativo responsabilizaria os protagonistas da lide, permitindo que exerçam suas capacidades de elaborar, eles mesmo, uma solução satisfatória e duradoura para ambos.

\section{A POSSIBILIDADE DA APLICAÇÃO DA JUSTIÇA RESTAURATIVA AOS CONFLITOS TRABALHISTAS}


Tendo sido talvez a primeira jurista brasileira a levantar a possibilidade de aplicação do modelo restaurativo na área trabalhista, Ana Maria S. R. de Barros, em trabalho intitulado "Justiça Restaurativa - Uma Justiça do Trabalho mais cidadã", apresentado no XIII Congresso Nacional de Magistrados da Justiça do Trabalho, em 2006, propôs a aplicação dos princípios e técnicas restaurativas em casos de acidente de trabalho, trabalho infantil e trabalho análogo ao de escravo.

Acerca da aplicação das técnicas restaurativas aos acidentes de trabalho, Lara menciona:

No que tange ao acidente de trabalho, uma infinidade de possibilidades de utilização de práticas de Justiça Restaurativa se apresenta. Uma perda de membro poderia gerar, por exemplo, além da indenização correspondente, um acordo restaurativo em que a empresa se comprometesse a custear 0 acompanhamento de profissionais especializados (psicólogos, médicos, fisioterapeutas, terapeutas ocupacionais). No acordo poderia constar também a obrigação de um o acompanhamento social mais próximo, de forma que as lições aprendidas pudessem se refletir na prevenção aos acidentes do trabalho na própria empresa. Pelo lado do empregado, surgiria a oportunidade de se expressar como o dano influiu no seu convívio familiar e de amizades, bem como na avaliação subjetiva que uma pessoa faz de si mesma (autoestima). As necessidades do acidentado poderiam ser atendidas de acordo com a singularidade de cada caso, isto é, o acidentado não viraria apenas mais um elemento na cadeia acidentária da seguridade social. Deixar-se-ia de se seguir a tendência jurisprudencial e do mercado securitário de tabelamento de valores para os diversos tipos de órgãos e membros do corpo humano e procurar-seiam respostas mais abrangentes para as necessidades do sujeito e das pessoas indiretamente afetadas pelo acidente de trabalho (2013, p 123).

Enquanto que Barros, por sua vez, também ao discorrer acerca da aplicação do modelo restaurativo nos casos de acidente de trabalho, propôs a seguinte reflexão:

Será possível continuarmos a trocar a saúde pela monetarização? Nenhuma indenização, por mais que acalente o coração pela via do bolso, é suficiente para compensar a perda de audição. Mais ainda, ao recebemos ações, como de LER e PAIR, miramos apenas o passado. Normalmente, essas doenças continuarão a macular um grande número 
DOI 10.20873/uft.2359-0106.2021.v8n2.p269-292

de empregados, por ser o modo de operação único naquela empresa. É mais barata a indenização do que adoção concreta de medida de segurança, educação do trabalhador e redução de carga horária. (...) Assim, sequer os juízes que julgaram ações similares contra o mesmo réu e sobre mesmo acidente mantêm contatos. É preciso, assim, não apenas indenizar, mas restaurar. Ou seja, sair exclusiva visão financeira, passando a incluir o social, o psicológico (auto-estima), o coletivo (ambiente de trabalho e o grupo) e círculo familiar (como a doença refletiu no seio doméstico e de amigos). O outro acréscimo, é que, ao invadir o chão da fábrica, retratará condições de trabalho vigentes: 1) como está a saúde dos atuais empregados e daqueles já demitidos (muitas doenças somente surgem algum tempo após a saída, como é o caso da asbestose)? 2) ajuda médica, psicológica e outras aos casos já detectados; 3) adoção de medidas preventivas; 4) fiscalização do Estado mais sistemática naquela empresa (o número de fiscais de trabalho é insuficiente, o que com largo espaço de tempo e muitas vezes por amostragem (2006, p.1).

De fato, percebe-se que o sistema jurídico brasileiro atual se restringe em compensar o dano pela fixação de um valor monetário que corresponde, em certa proporção, à extensão da perda havida. Cumpre, todavia, seja feita uma reflexão acerca da suficiência dessa compensação indenizatória, conforme bem questiona Lara

A fixação de valores e a condenação para o pagamento são, por si só, suficientes para a compensação de um acidente de trabalho que deixe sequelas a um trabalhador? Outros tipos de obrigações, como por exemplo, o custeio de acompanhamento psicológico e social, bem como o acompanhamento por profissional de saúde do período de adaptação do trabalhador a eventuais próteses que ele tenha que utilizar, poderiam ser acordadas por empregado e empregador em um encontro restaurativo, para além da indenização? Os Tribunais do Trabalho teriam condições de manter em seus quadros equipes interdisciplinares (psicólogos e assistentes sociais) para a realização desses encontros, a fim de fosse dado tratamento adequado ao conflito, a partir da lente restaurativa, de acordo com a singularidade de cada caso? (2013, p. 189).

O que se reflete, neste caso, é a possibilidade de que a solução trabalhista seja muito mais ampla do que apenas uma espécie de indenização, mas sim que seja singular para cada caso, conforme a necessidade. Denota-se que poderiam ser 
definidas diversas outras formas de obrigações e acoro entre as partes, de modo que o empregador lesado poderia, por exemplo, além de receber a indenização pelos danos sofridos, ser beneficiado com um acompanhamento por profissional médico até que tenha condições de retornar ao trabalho, de modo a garantir de maneira eficaz a sua recuperação para retornar ao trabalho.

Para Melhem e Rosa (2016, p. 150) aplicação dos círculos restaurativos em algumas outras hipóteses, tais como: os casos em que houve prática de assédio moral; casos de acidente de trabalho causados por colegas trabalhadores ou ainda em acidentes em que houve culpa recíproca dos envolvidos; em situações preventivas, como no processo de construção e manutenção de um bom relacionamento entre trabalhadores e entre estes e seus empregadores; além dos casos de reintegração do trabalhador ao posto de trabalho.

No que se refere à reintegração no trabalho, Lara salienta que:

A abordagem da Justiça Restaurativa poderia trazer nova luz para velhas questões trabalhistas. Um dos problemas comuns vistos na Justiça do Trabalho é o da reintegração do trabalhador com estabilidade provisória de emprego, como é, por exemplo, o caso dos trabalhadores membros da CIPA (art. 10, inciso II, alínea "a" do ADCT), da gestante (art. 10, II, "b" do ADCT), do dirigente sindical (art. 8 da CR e art. 543, parágrafo $3^{\circ}$ da CLT), dos dirigentes de cooperativa (art. 55 da Lei $n^{\circ}$ $5.764 / 71$ ) e dos trabalhadores que sofreram acidente de trabalho (art. 118 da Lei no 8.213/91) (2013, p. 71).

Conforme Lara o modelo processual atual, nesses casos em que se discute a estabilidade e à reintegração ao trabalho, caso reste frustrada a conciliação, o juiz tem dois caminhos a seguir: determinar a reintegração do trabalhador injustamente dispensado ou aplicar a sanção prevista no art. 496 da Consolidação das Leis do Trabalho, ou seja, o juiz tem que tomar uma decisão verdadeiramente difícil, que tem o risco de submeter uma pessoa a voltar ao trabalho num ambiente hostil ou até mesmo de deixar um trabalhador apto e com vontade de trabalhar em sua residência, além de determinar o pagamento de direitos integrais a uma empresa que poderia receber a força de trabalho do empregado em efetiva reintegração, (2013, p. 72) . 
No caso acima mencionado seria perfeitamente aplicável o método restaurativo, o qual contribuiria para o esclarecimento da situação ocorrida entre as partes, facilitaria a superação da questão emocional que estivesse impedindo a volta do empregado ao labor e, principalmente, favoreceria a continuidade da relação de trabalho, garantindo, assim, o princípio da continuidade da relação de emprego, que segundo Delgado é um dos princípios mais importantes do Direito do Trabalho:

[...] é de interesse do Direito do Trabalho a permanência do vínculo empregatício, com a integração do trabalhador na estrutura e dinâmica empresariais. Apenas mediante tal permanência e integração é que a ordem justrabalhista poderia cumprir satisfatoriamente o objetivo teleológico do Direito do Trabalho, de assegurar as melhores condições, sob a ótica obreira, de pactuação e gerenciamento da força de trabalho em determinada sociedade. (2019, p. 246).

Outro Melhem e Rosa, (2016, p. 166) aspecto positivo da aplicação da Justiça Restaurativa no Direito do Trabalho seria uma possível redução do aspecto meramente monetário que caracteriza as relações trabalhistas, tanto do ponto de vista do empregado (que muitas vezes busca incontáveis lucros com uma Ação Reclamatória), como do ponto de vista do empregador (que não são poucas as vezes em que deliberadamente deixa de cumprir com seus deveres para reduzir seu impacto financeiro em um acordo trabalhista), vez que por meio da justiça restaurativa os aspectos humanos envolvidos seriam melhor considerados e assim futuros abusos poderiam ser evitados.

A justiça restaurativa também poderia ser utilizada, no processo do trabalho, nos casos em que se discute a justa causa ou a culpa recíproca, pois tanto o trabalhador, quanto o empregador, tentam ao máximo evitar este tipo de situação. Isso porque para o empregado, segundo o que defende o art. 484 da CLT, o reconhecimento da justa causa ou da culpa recíproca representa a redução de metade da indenização que seria devida em caso de culpa exclusiva do empregador, enquanto que para o empregador, se fosse 0 caso em que o trabalhador seria dispensado por justa causa, caberia àquele 
pagar forçosamente a metade desses valores. Logo, denota-se conforme Lara (2013, p. 71) em tais situações a reconstituição de um bom diálogo entre as partes, possibilitada pela abordagem restaurativa, poderia proporcionar o esclarecimento detalhado, do problema trazido, o que tenderia a favorecer um acordo entre os envolvidos.

Não bastasse todas as hipóteses já elencadas, denota-se que também seria possível aplicar os procedimentos restaurativos quando a demanda trabalhista for originária de pequenas empresas, vez que nessas ocasiões a ligação emocional das pessoas no ambiente de trabalho tende geralmente a ser maior, como as demandas em torno do trabalho doméstico, por exemplo.

Consoante elencado, pode-se visualizar inúmeros casos, segundo Melhem e Rosa (2016, p. 160) em que as formas restaurativas podem ser aplicadas à Justiça Trabalhista, métodos que certamente contribuem para que o cidadão saia da presença do Poder judiciário com a sensação de que efetivamente foi atendido, uma vez que se trata, sem dúvida alguma, de um importante meio de humanização das soluções de conflitos em geral e inclusive dos conflitos trabalhistas..

Para a realização de tais propostas, seria interessante manter equipes multidisciplinares em atuação nas Varas do Trabalho, de modo que quando o magistrado percebesse que o conflito seria melhor resolvido mediante a utilização das práticas da Justiça Restaurativa, poderia encaminhar tal caso à referida equipe para solução, além de que seria interessante, também, a celebração de convênios com instituições de ensino que tenham pessoas capacitadas para conduzir os círculos restaurativos, como as universidades, por exemplo.

Pois para que seja possível a implementação desta forma restaurativa de solução de conflitos, é necessário que haja um esforço conjunto dos agentes do judiciário, do meio acadêmico e do meio comunitário, com o propósito de assegurar uma nova forma de se pensar e de se fazer justiça. Uma forma diferenciada que traga novas possibilidades para o enfrentamento de certos problemas para os quais o atual sistema de justiça não tem encontrado respostas totalmente satisfatórias, deixando à deriva aqueles cujos direitos ainda não estão totalmente consolidados. 
DOI 10.20873/uft.2359-0106.2021.v8n2.p269-292

\section{CONSIDERAÇÕES FINAIS}

Após uma ampla análise a respeito dos casos em que se poderia aplicar o método restaurativo, pontua-se que a Justiça Restaurativa é perfeitamente compatível com a Justiça do Trabalho, funcionando, inclusive, como um importante instrumento para a democratização das relações de trabalho e também das próprias relações sociais.

Conforme observado no texto, é evidente que nem toda questão trabalhista poderia ser submetida à Justiça Restaurativa, como por exemplo as situações que girem em torno apenas de obrigações pecuniárias, bem como aquelas em que as partes se recusarem a se submeter aos círculos. Nas primeiras porque se tratando apenas de obrigações pecuniárias, não haveria o que, de fato, "restaurar", enquanto que nas segundas, trabalha-se com a ideia de que no processo restaurativo a consensualidade é um dos elementos essenciais, sendo imperiosa a manifestação de vontade de ambas as partes, pois se elas não possuírem interesse, o círculo restaurativo não poderá ser realizado.

Entretanto, em que pese haver situações em que não seja possível a aplicação das medidas restaurativas, é perfeitamente possível que os Tribunais Regionais do Trabalho experimentem as práticas restaurativas para o tratamento de alguns tipos de conflitos, tais como os que envolvem as temáticas de acidente de trabalho causados por colegas trabalhadores ou com culpa recíproca, a reintegração dos trabalhadores com estabilidade provisória de emprego, em conflitos nas empresas com número restrito de empregados, além de outros relacionados com o trabalho doméstico e, principalmente, em situações preventivas, na construção e manutenção de bom relacionamento entre trabalhadores e empregadores, buscando uma solução eficaz para as demandas trabalhistas e que satisfaça ambas as partes.

\section{REFERÊNCIAS}


BARROS, Ana Maria Soares R. de. Justiça Restaurativa - Uma Justiça do Trabalho mais cidadã. Trabalho apresentado no XIII Congresso Nacional de Magistrados da Justiça do Trabalho, 2006.

BRASIL. Decreto-Lei no 5.452, de 1ำ de Maio de 1943. Aprova a Consolidação das Leis do Trabalho (CLT). Disponível em: http://www.planalto.gov.br/ccivil_03/decretolei/del5452.htm. Acesso em:12 Abr. 2020.

. Constituição da República Federativa do Brasil de 1988. Disponível em: http://www.planalto.gov.br/ccivil_03/constituicao/constituicaocompilado.htm. Acesso em:12 Abr. 2020.

. Lei № 13.105, de 16 de Março de 2015. Código de Processo Civil. Disponível em: http://www.planalto.gov.br/ccivil_03/_ato2015-2018/2015/lei//13105.htm. Acesso em:12 Abr. 2020.

CASSAR, Vólia Bomfim. Direito do trabalho. 11. ${ }^{a}$ ed. rev. e atual. Rio de Janeiro: Forense; São Paulo: MÉTODO, 2015.

CNJ. Conselho Nacional de Justiça. Justiça em Números 2019. Brasília: 2019.

CNJ. Conselho Nacional de Justiça. Resolução № 125 de 29/11/2010. Dispõe sobre a Política Judiciária Nacional de tratamento adequado dos conflitos de interesses no âmbito do Poder Judiciário e dá outras providências. Disponível em:https://atos.cnj.jus.br/atos/detalhar/atos-normativos?documento=156. Acesso em:12 Abr. 2020.

. Conselho Nacional de Justiça. Resolução № 225 de 31/05/2016. Resolução № 225 de 31/05/2016. Disponível em: https://atos.cnj.jus.br/atos/detalhar/atosnormativos?documento=2289. Acesso em:12 Abr. 2020.

. Conselho Nacional de Justiça. Resolução № 225 de 31/05/2016. Disponível em: Acrescenta os artigos 28-A e 28-B à Resolução $C N J n^{\circ} 225$, de 31 de maio de 2016, a qual dispõe sobre a Política Nacional de Justiça Restaurativa no âmbito do Poder Judiciário e dá outras providências. Acesso em:12 Abr. 2020.

DELGADO, Maurício Godinho. Curso de Direito do Trabalho. Mauricio Godinho Delgado. 18. ed. São Paulo: LTr, 2019.

LARA, Caio Augusto Souza. A justiça restaurativa como via de Acesso à Justiça. 2013. Dissertação (Mestrado em Direito) - Universidade Federal de Minas Gerais, Belo Horizonte, 2013. 
JORGE NETO, Francisco Ferreira; CAVALCANTE, Jouberto de Quadros Pessoa. Direito Processual do Trabalho. 8. ed. São Paulo: Atlas, 2019.

LEITE. Carlos Henrique Bezerra. Curso de direito processual do trabalho. 17. ed. São Paulo: Saraiva Educação, 2019.

MELHEM, Patricia Manente. ROSAS, Rudy Heitor. Justiça Restaurativa e Justiça do Trabalho no Brasil: um Encontro Possível. Formas consensuais de solução de conflitos I [Recurso eletrônico on-line] organização CONPEDI/UdelaR/ Unisinos/URI/UFSM /Univali/UPF/FURG; Coordenadores: Charlise Paula Colet Gimenez, Mariella Bernasconi - Florianópolis: CONPEDI, 2016. p.150 - 166 Disponível em: $\quad$ www.conpedi.org.br/publicacoes/910506b2/6jq67a8y/16Q2Ub0U4905wvYl.pdf. Acesso em: 09 dez. 2019.

NOGUEIRA, Jessica Silva. A humanização da Justiça: Conciliação, Mediação e Justiça Restaurativa. Set. 2018. Disponível em: <https://jus.com.br/artigos/68980/ahumanizacao-da-justica>. Acesso em: 06 dez. 2018.

ORSINI, Adriana Goulart de Sena. LARA, Caio Augusto Souza. A Justiça Restaurativa: uma abrangente forma de tratamento de conflitos. Disponível em: $<$ http://as1.trt3.jus.br/bd-

trt3/bitstream/handle/11103/2665/adriana_sena_justica_restaurativa.pdf?sequence $=1$ > . Acesso em: 06 dez. 2018.

PINTO, Renato Sócrates Gomes. Justiça Restaurativa é Possível no Brasil? In: SLAKMON, C., R. De Vitto, e R. Gomes Pinto, 2005 (Brasília-DF: Ministério da Justiça e Programa das Nações Unidas para o Desenvolvimento). Disponível em: $<$ www.un.org/ruleoflaw/files/Justice_Pub_Restorative\%20Justice.pdf>. Acesso em: 09 dez 2019.

ROSENBERG, Marshall B. Comunicação não-violenta: técnicas para aprimorar relacionamentos pessoais e profissionais. Trad. Mário Vilela. São Paulo: Ágora, 2006.

SCHWINN, Simone Andrea. GÖSSLING, Luciana Manica. Por uma cultura de paz: a justiça restaurativa enquanto mecanismo de resolução de conflitos. Trabalho apresentado no I Seminário Internacional de Mediação de Conflitos e Justiça Restaurativa, 2013.2 Disponível em: $<$ http://online.unisc.br/acadnet/anais/index.php/mediacao e jr/article/view/10934/1463>. Acesso em: 10 dez. 2019. 
DOI 10.20873/uft.2359-0106.2021.v8n2.p269-292

SCURO NETO, Pedro. A Justiça como Fator de Transformação de Conflitos: Princípios e Implementação. (2000). Recuperado de <http://www.restorativejustice.org/rj3/Full- text/brazil/EJRenato\%20_Nest_.pdf $>$. Acesso em: 10 dez. 2019.

SIMÕES, Ana Paula Arrieira. AQUINO, Quelen Brondani. A Justiça Restaurativa nos conflitos de gênero em ambiente de trabalho: práticas restaurativas para relacionamentos produtivos. Trabalho apresentado no XI Seminário Internacional de Demandas Sociais e Políticas Públicas na Sociedade Contemporânea, 2014. Disponível em: $\quad<$ http://online.unisc.br/acadnet/anais/index.php/sidspp/article/view/11773/1552> Acesso em: 09 dez. 2019.

ZEHR, Howard. Trocando as lentes: um novo foco sobre o crime e a Justiça. Tradução de Tônia Van Acker. São Paulo: Palas Athena, 2008.

TIVERON, Raquel. Justiça restaurativa. A emergência da cidadania na dicção do direito. A construção de um novo paradigma da justiça criminal. Brasília, DF: Trampolin, 2017. 